\title{
CONTROLE DE PLANTAS DANINHAS COM HERBICIDAS NA CULTURA DO FEIJÃO (Phaseolus vulgaris L.)
}

\author{
L.S.P. CRUZ* \& N. GRASSI**
}

* Pesquisador Científico do Instituto Biológico. Seção de Herbicidas. Atualmente no Instituto Agronômico. Caixa Postal 28, 13.100 - Campinas, SP.

** Engenheiro Agrônomo do Instituto Biológico, Seção de Herbicidas. Atualmente na Hoechst do Brasil Química e Farmacêutica S/A. Caixa Postal 7333. 01000 - São Paulo, SP.

\section{RESUMO}

Foi realizada uma pesquisa em 1970, para se conhecer os efeitos de três herbicidas aplicados em pré-plantio incorporado (EPTC a 3,60 kg/ha, nitralin e trifluralin a $0,76 \mathrm{~kg} / \mathrm{ha}$ ) e de um em pré-emergência (fluorodifen a $3,00 \mathrm{~kg} / \mathrm{ha}$ ) na cultura de feijão comparados com uma testemunha sem herbicida.

As duas gramineas presentes no ensaio, Eleusine indica (L.) Gaertn. e Digitaria sanguinalis (L.) Scop. foram eficientemente controladas por todos os herbicidas, com indices de controle superiores a $87,00 \%$, em contagem de plantas daninhas realizada 29 dias após a aplicação dos herbicidas. Dentre as dicotiledóneas presentes, Ama ranthus viridis L. também foi eficientemente con trolado por todos os herbicidas, com indices de controle superiores a 92,00\%. Ageratum conyzoides L. foi eficientemente controlado por fluorodifen $(91,60 \%)$ e regularmente por EPTC $(78,99 \%)$ e por nitralin $(79,83 \%)$. Trifluralin não foi eficiente contra A. conyzoides $\mathrm{L}$.

Nenhum dos herbicidas testados controlou Ipomoea sp e Chenopodium ambrosioides L., também presentes no experimento.

EPTC e nitralin apresentaram as menores porcentagens de infestação geral de plantas daninhas, tendo, aos 51 dias da aplicação dos produtos, quando suas parcelas foram capinadas mecanicamente, 8,00 e 17,00\% de infestação, respectivamente. Trifluralin e fluorodifen precisaram de limpeza aos 42 dias da aplicação, e a testemunha já aos 29 dias, pois apresentavam parcelas com $25,00 \%$, ou mais, de infestação, naquelas épocas.

Os herbicidas experimentados não foram prejudiciais à germinação e ao desenvolvimento vegetativo dos feijoeiros, assim como à sua produ ção de grãos.

PALAVRAS CHAVE: controle de plantas daninhas, herbicidas, feijão.

\section{SUMMARY}

WEED CONTROL IN BEANS (Phaseolus vulgaris L.) WITH HERBICIDES

The weed control with herbicides in beans crop was studied during 1970 year, in Campinas-SP, on a sandy-loam soil. The treatments employed were EPTC at $3.60 \mathrm{~kg} / \mathrm{ha}$, nitralin and trifluralin at $0.76 \mathrm{~kg} / \mathrm{ha}$, all applied in preplant $\mathrm{i}$ porated; fluorodifen in preemergence at $3.00 \mathrm{~kg} / \mathrm{ha}$ and a hoed check.

Among the weeds presents in the experiment, Amaranthus viridis . L., Eleusine indica (L.) Gaertn. and Digitaria sanguinalis (L.) Scop. were very well controled by the herbicides in general. Good control was obtained by fluorodifen against Ageratum conyzoides L.. None efficiency was observed to Chenopodium ambrosioides L. and Ipomoea sp. by the chemicals.

The herbicides did not cause injury to the beans.

KEYWORDS: weed control, herbicides, beans

\section{INTRODUÇÃO}

O controle de plantas daninhas -na cultura do feijão reveste-se de grande importância na obtenção de altos rendimentos por ser essa cultura de ciclo curto, onde a con corrên cia que o mato lhe faz é o principal fator a ser considerado.

O emprego de herbicidas para o controle das plantas daninhas é prática agrícola que vem se tornando obrigató- 
ria, principalmente em se considerando as dificuldades atuais na obtenção de mão-de-obra econômica e eficiente.

As pesquisas envolvendo aplicação de herbicidas em leguminosas, conduzidas na Seção de Herbicidas do Instituto Biológico, tiveram início em $1961 \mathrm{com}$ os estudos de dinoseb e dinoseb acetato em cultura do amendoim (3). Com feijão poucos resultados foram divulgados (4, 5).

Atualmente, constituindo-se o feijão uma cultura de grande importância econômica para o Brasil, procurou-se divulgar os resultados de pesquisa desenvolvida em 1970 com herbicidas indicados para uso nessa cultura, que ainda se encontram no mercado apesar do aparecimento de outros mais moder$\operatorname{nos}(1,5,6)$.

\section{MATERIAIS E MÉTODOS}

O experimento foi conduzido em área da Estação Experimental de Campinas, do Instituto Biológico, sobre um solo com as seguintes características: argila $22,5 \%$, areia fina $31,3 \%$, areia grossa $36,2 \%$, limo $10,0 \%$, matéria orgânica $1,3 \%$ e pH 517.0

plantio do feijão cv. Roxinho e a aplicação dos herbicidas foram realizados em 03.03.70 com tratamentos obedecendo um delineamento estatístico em blocos ao acaso e cinco repetições, com parcelas de $20,00 \mathrm{~m}^{2}(4,00 \times 5,00 \mathrm{~m})$ com 10 fileiras espaçadas de $0,40 \mathrm{~m}$ cada uma.

A aplicação dos herbicidas foi realizada com pulverizador costal, manual, com capacidade para 20 litros, munido de um bico de jato em leque 80.03, com um gasto de calda correspondente a $5001 /$ ha.

Os herbicidas testados foram EPTC(') na dose de $3,60 \mathrm{~kg} / \mathrm{ha}$, nitralin( $\left.{ }^{2}\right)$ e trifluralin( $\left.{ }^{3}\right)$ a $0,76 \mathrm{~kg} /$ /ha, aplicados em pré-plantio com incorporação imediata ao solo com grade de discos trabalhando a uma profundidade de $0,15 \mathrm{~m}$; e fluorodifen(4) a $3,00 \mathrm{~kg} / \mathrm{ha}$, aplicado em pré-emergência da cultura e das plantas daninhas. Constou do ensaio também, um tratamento testemunha, sem herbicida.

Aos 29 dias após a aplicação dos herbicidas foi realizada avaliação de infestação natural de plantas daninhas da área do experimento, com contagem em área correspondente a $5 \%$ da parcela, assim como os efeitos do produto sobre as mesmas, em comparação com a testemunha sem herbicida.

(1) Usado na formulação comercial de Eptam $6 \mathrm{E}$

(2) Usado na formulação comercial de Planavin 4

(3) Usado na formulação comercial de Treflan

( $\left.{ }^{4}\right)$ Usado na formulação comercial de Preforan
Aos 29, 42 e 51 dias da aplicação foram avaliadas as porcentagens de infestação geral de plantas daninhas de cada tratamento, considerando-se o valor médio do resultado da observação visual realizada por dois técnicos.

Quando pelo menos uma parcela do tratamento atingia $25,00 \%$ de infestação, todas as parcelas do tratamento eram capinadas mecanicamente, e assim mantidas isentas de mato até a realização da colheita.

As avaliações dos efeitos dos herbicidas sobre a própria cultura foram determinadas pela contagem do número de plantas existentes em cada parcela antes do desbaste, realizado 30 dias após o plantio; por observações visuais de possiveis sintomas de fitotoxicidade; e, pela produção de grãos obtidos na colheita.

As plantas daninhas que apareceram em maior número e freqüência foram:

Monocotiledôneas -

Digitaria sanguinalis (L.) Scop. capim-colchão Eleusine indica (L.) Gaertn. capim-pé-degalinha

Dicotiledôneas -

Agaratum conyzoides L. mentrasto Amaranthus viridis L. carurú Chenopodium ambrosioides L. quenopódio Ipomoea sp cipó

\section{RESULTADOS E DISCUSSÃO}

No quadro 1 estão as es pécies de mato presentes no experimento, assim como os efeitos dos herbicidas sobre as mesmas, após 29 dias da aplicação dos herbicidas.

A porcentagem de infestação geral do mato e as épocas em que foi necessário efetuar a primeira capina mecânica do tratamento, estão relacionadas no quadro 2 .

Os efeitos dos herbicidas sobre a cultura podem ser verificados pelo estudo do quadro 3.

Todos os herbicidas foram eficien tes no controle das duas gramíneas do ensaio, $E$. indica e $D$. sanguinalis, assim como no de A. viridis, com índices de controle superiores a 85,00\%. Resultados de pesquisas de Grassi \& Leiderman (2), com am endoim, confirmam aqueles obtidos por EPTC, nitralin e trifluralin, contra as gramíneas. Os resultados de controle das monocotiledôneas por EPTC coincidem também com os de Alcân tara (1) e de Rozanski \& Santos (5); porém, os resultados do tratamento com fluorodifen a $3,00 \mathrm{~kg} / \mathrm{ha}$ diferem dos de Alcântara (1) a $3,60 \mathrm{~kg} / /$ ha. 
Quadro 1. Avaliaçáo dos efeitos dos herbicidas, 29 dias após a aplicaçáo, com contagem das plantas daninhas, com dados transformados em porcentagem de controle em relação às parcelas testemunhas, em experimento com feijấo. Os dados sảo médias de cinco repetiçóes. Data da aplicaçáo dos herbicidas: 03/03/70.

\begin{tabular}{|c|c|c|c|c|c|c|c|c|c|}
\hline \multirow[b]{2}{*}{ Herbicides } & \multirow{2}{*}{$\begin{array}{l}\text { Modo de } \\
\text { aplicą̧̃ó }\end{array}$} & \multirow[b]{2}{*}{ Doset } & \multicolumn{6}{|c|}{ Controle de phantas daninhas } & \multirow{2}{*}{$\begin{array}{l}\text { Controle } \\
\text { genal }\end{array}$} \\
\hline & & & $\begin{array}{l}\text { Eleusine } \\
\text { indica }\end{array}$ & $\begin{array}{l}\text { Digitari } \\
\text { anguinalis }\end{array}$ & Ipomoen sp & $\begin{array}{l}\text { Ageratum } \\
\text { conyzoides }\end{array}$ & $\begin{array}{l}\text { Chenopodium } \\
\text { ambrosioides }\end{array}$ & $\begin{array}{l}\text { Amananthus } \\
\text { viridis }\end{array}$ & \\
\hline & & $\mathrm{kg} / \mathrm{ha}$ & $\%$ & $\%$ & $\%$ & $\%$ & $\%$ & $\%$ & $\%$ \\
\hline EPTC & $\begin{array}{l}\text { pré-plantio } \\
\text { incorporado }\end{array}$ & 3,60 & 98,81 & 87,18 & 62,42 & 78,99 & 38,60 & 97,56 & 78,69 \\
\hline Nitralin & $\begin{array}{l}\text { pré-plantio } \\
\text { incorporado }\end{array}$ & 0,76 & 95,62 & 97,44 & 57,37 & 79,83 & 38,60 & 92,68 & 73,40 \\
\hline Triffuralin & $\begin{array}{l}\text { pre-plantio } \\
\text { incorporado }\end{array}$ & 0,76 & 96,42 & 87,18 & 50,00 & 3,36 & 7,02 & 95,12 & 57,84 \\
\hline Fluorodifen & pré-emergência & 3,00 & 88,85 & 97,44 & 65,79 & 91,60 & 33,33 & 100,00 & 76,66 \\
\hline Testemunha & $\begin{array}{l}\text { (infestação média } \\
\text { por } \mathrm{m}^{2} \text { ) }\end{array}$ & & 251 & 39 & 380 & 119 & 57 & 41 & 887 \\
\hline
\end{tabular}


Quadro 2. Avaliação dos efeitos dos herbicidas sobre as plantas daninhas existentes no experimento com feijão, em porcentagem geral de infestação. Os dados são médias de cinco repetições. Data da aplicação dos herbicidas 03/03/70.

\begin{tabular}{|c|c|c|c|c|c|}
\hline \multirow{2}{*}{ Herbicidas } & \multirow{2}{*}{$\begin{array}{l}\text { Modo de } \\
\text { aplicaçãa }\end{array}$} & \multirow{2}{*}{ Doses } & \multicolumn{3}{|c|}{ Infestação de mato } \\
\hline & & & Após 29 días & Após 42 dias & Após 51 dias \\
\hline & & $\mathrm{kg} / \mathrm{ha}$ & $\%$ & $\%$ & $\%$ \\
\hline EPTC & $\begin{array}{l}\text { pré-plantio } \\
\text { incorporado }\end{array}$ & 3,60 & 3,40 & 4,80 & $8,00^{*}$ \\
\hline Nitralin & $\begin{array}{l}\text { pro-plantio } \\
\text { incorporado }\end{array}$ & 0,76 & 6,80 & 5,00 & $17,00^{*}$ \\
\hline Trifluralin & $\begin{array}{l}\text { pré-plantio } \\
\text { incorporado }\end{array}$ & 0,76 & 10,20 & $14,00^{*}$ & \\
\hline $\begin{array}{l}\text { Fluorodifen } \\
\text { Testemunha }\end{array}$ & pré-emergência & 3,00 & $\begin{array}{c}5,40 \\
25,00^{*}\end{array}$ & $10,00^{*}$ & \\
\hline
\end{tabular}

* Capinado nesta data.

Quadro 3. Avaliaçào dos efeitos dos herbicidas sobre o númerode plantas de feljăo e sobre a pro. ào em peso de grảos. Dados médios de cinco repetiçóes.

\begin{tabular}{|c|c|c|c|c|}
\hline Herbicidas & Modo de aplicaçĩo & Doses & Número de plantas & Produçäo \\
\hline EPTC & $\begin{array}{l}\text { pré-plantio } \\
\text { incorporado }\end{array}$ & $\begin{array}{l}\mathrm{kg} / \mathrm{ha} \\
3,60\end{array}$ & $\underset{7,20}{(\operatorname{transf} .} \sqrt{x})$ & $\begin{array}{l}\mathrm{kg} / \mathrm{ha} \\
1967,5\end{array}$ \\
\hline Nitralin & $\begin{array}{l}\text { pré-plantio } \\
\text { incorporado }\end{array}$ & 0,76 & 7,00 & 2058,6 \\
\hline Trifluralin & $\begin{array}{l}\text { pré-plantio } \\
\text { incorporado }\end{array}$ & 0,76 & 7,53 & 2062,0 \\
\hline $\begin{array}{l}\text { Fluorodifen } \\
\text { Testemunha }\end{array}$ & pré-emergência & 3,00 & $\begin{array}{l}6,75 \\
6,67\end{array}$ & $\begin{array}{l}1974,6 \\
1985,6\end{array}$ \\
\hline
\end{tabular}

A. conyzoides foi muito bem controlado por fluorodifen $(91,60 \%)$ e regularmente por EPTC $(78,99 \%)$ e nitral in $(79,83 \%)$.

Os herbicidas experimentados não controlaram Ipomoea sp $(<66,00 \%)$ e C. ambrosioides (<39,00\%).

Quando se considerou o controle geral das plantas daninhas os melhores resultados foram dados por EPTC e fluorodifen, com índices superiores a $75,00 \%$.

O estudo do quadro 2 mostra que a testemunha sem herbicida precisou de capina aos 29 dias do plantio; os tratamentos com trifluralin e fluorodifen foram capinados com 42 dias; e, EPTC e nitralin somente precisou da primeira capina mecânica aos 51 dias da aplicação.

Os resultados das análises da variância do número de plantas de feijão, obtido antes do desbaste, e de produção de grãos (quadro 3) mostram que esses fatores não foram prejudicados pelos tratamentos com herbicida, para o cv. Roxinho.

Pelos resultados obtidos, pode-se concluir que EPTC a 3,60 kg/ha e nitralin a $0,76 \mathrm{~kg} / \mathrm{ha}$ foram mais eficientes do que trifluralin a $0,76 \mathrm{~kg} /$ ha e fluorodifen a $3,00 \mathrm{~kg} / \mathrm{ha}$, para o controle de plantas 
daninhas em culturas de feijão com população predominante de E. indica, $D$. sanguinalis, Ipomoea sp, A. conyzoides, C. ambrosioides e $A$. viridis.

\section{LITERATURA CITADA}

1. Alcântara, E.N.. Herbicidas na cultura do feijâo (Phaseolus vulgaris) In: Sem. Bras. Herb. Ervas Dan. XII, Inéus/Itabuna, 1980. Resumos, p.13-14, 1980

2. Grassi, N. \& Lelderman, L. Controle químico das ervas daninhas em amendolm. In: Cong. Nac. Bot. XXIV, Pelotas, 1973. Resumos, p. 16, 1973.
3. Kramer, M. \& Leiderman, L..Controle de ervas daninhas do amendoim pela aplicaçáo de herbicidas de préemergencia. Arq. Inst. Biol. 28:175-184, 1961.

4. Leiderman, L. \& Santos, C.A.L.. Controle préermergente de plantas daninhas na cultura do fejjăo. In: Enc. Tec. Agr., I. Campinas, 1964. Resumos, n. ${ }^{\circ} 32,1964$.

5. Rozanski, A. \& Santos, C.A.L.. Avallaçấo de herbicidas na cultura do feljoeiro. In: Sem. Bras. Herb. Ervas Dan., XIII, Ilhéus/Itabuna, 1980. Resumos, p. 13, 1980.

6. Sá, M.E. \& Panizzi, R.C.. Controle químico de plantas daninhas em feijấo (Phaseolus vulgaris) em prémergencla. In: Sem. Bras. Herb. Ervas Dan. XIII, Ilhéus/Itabuna, 1980. Resumos, p. 14, 1980. 